\title{
Educação Patrimonial como forma de Educação Informal: Uma reflexão
}

\section{Patrimonial Education as Informal Education: A reflection}

\author{
Simone Pereira Taguchi Borges ${ }^{1,2}$ \\ Fábio de Padua Nakano ${ }^{1}$ \\ Cristhian Cera de Matos ${ }^{1}$ \\ Sara Jeiéle Leone Rosa ${ }^{3}$ \\ Rosinei Ribeiro Batista ${ }^{1,2,3}$ \\ Luiz Antônio Borges Júnior ${ }^{2}$
}

\section{Resumo}

A "Educação Patrimonial" é um processo permanente e sistemático de trabalho educacional centrado no Patrimônio Cultural como fonte primária de conhecimento e enriquecimento individual e coletivo. Essa metodologia engloba inúmeras estratégias utilizadas para levar às comunidades ao contato direto com as evidências e manifestaçôes da cultura, em todos seus múltiplos aspectos, sentidos e significados, que são produzidos nas pesquisas arqueológicas. Normalmente, são realizadas atividades de campo, visitas monitoradas a laboratórios de arqueologia, design e engenharia, aulas expositivas, oficinas, dentre outros, com o objetivo de envolver a comunidade com o sítio arqueológico. Essas açôes afirmativas trazem novos padrões de cultura à comunidade e indiretamente altera o perfil educacional e comportamento social da regiáo, levando a um processo ativo de conhecimento, apropriação e valorização de sua herança cultural.

Palavras-chave: Educação Patrimonial, sítio arqueológico, cerâmicas indígenas

\section{Abstract}

The "Patrimonial Education" is an ongoing and systematic educational effort focused on Cultural Patrimonial as a primary source of knowledge and enrich individual and collective. This methodology encompasses many strategies used to provide the communities to direct contact with the evidence and expressions of culture in its all aspects and meanings, which are produced in archaeological research. They are usually carried out field activities, guided visits to archaeological laboratories, design and engineering, lectures, workshops, among others, in order to involve the community with the archaeological site. These affirmative action brings new standard of culture to the community and indirectly affects the profile of education and social behavior of the region, leading to an active process of knowledge, ownership and appreciation of their cultural heritage.

Keywords: Patrimonial Education, archaeological site, aboriginal ceramics. 


\section{INTRODUÇÃO}

A educação patrimonial nada mais é do que uma proposta interdisciplinar de ensino voltada para questóes atinentes ao patrimônio cultural. Compreende desde a inclusão nos currículos escolares, de conteúdos programáticos que versem sobre o conhecimento e a conservação do patrimônio histórico, até a realização de cursos de aperfeiçoamento e extensão para os educadores e a comunidade em geral. Sempre com o objetivo de propiciar informaçóes acerca do acervo cultural, de forma a despertar nos educadores e na sociedade, o senso de preservação da memória histórica e o conseqüente interesse pelo tema (1).

A Constituiçấo de 1988 passa a tratar a cultura e os bens culturais de forma mais aprofundada, destinando uma seção específica ao assunto, reconhecendo e protegendo o pluralismo cultural e a diversidade de valores dos grupos étnicos integrantes do nosso "processo civilizatório", dando destaque aos grupos indígenas e afro-brasileiros. $\mathrm{O}$ artigo 216 , e respectivo inciso $\mathrm{V}$, consideram patrimônio cultural os conjuntos e sítios de valor arqueológico, prevendo para estes, pelo parágrafo $1^{\circ}$, as seguintes formas de proteção (as mesmas previstas para os bens culturais em geral): inventários; registros; vigilância; tombamento; desapropriação; outras formas de acautelamento e preservação. Porém, os órgãos criados para proteger os bens culturais permaneceram, por muito tempo, debilitados e com pouca estrutura. Com dificuldades até para cumprir seu papel formal elementar, os órgãos públicos em muito se distanciaram das comunidades, o que aumentou as atribuiçóes das universidades, de seus pesquisadores e dos centros de pesquisa. Reconhecendo que uma política centralizadora dificulta a preservação, a Constituição Federal assegura, no artigo 216, $\$ 1^{\circ}$, a colaboraçáo da comunidade para promover e proteger o patrimônio cultural brasileiro (2).

Em Hartog (2006, p. 261-273):

O patrimônio se impôs como a categoria dominante, englobante, senão devorante, em todo caso, evidente, da vida cultural e das políticas públicas. Na França, desde 1983, as Jornadas do Patrimônio atraíram cada vez mais visitantes aos imóveis ditos do Patrimônio: mais de onze milhôes em setembro de 2002. Esses resultados, devidamente estabelecidos e proclamados a cada ano pela mídia, são como um recorde a bater no ano seguinte. As Jornadas do Patrimônio têm se disseminado por todo o mundo e fala-se hoje, sobretudo, por meio das iniciativas e das convenções da UNESCO, de universalização do patrimônio, enquanto que, a cada ano, se alonga a lista dos sítios do patrimônio universal da humanidade (3).
O dia 17 de agosto de 1998 foi instituído como o "Dia Nacional do Patrimônio Histórico", cem anos após a data de nascimento do Rodrigo Melo Franco de Andrade. Ele, além de ser advogado, jornalista e escritor, foi criador do Instituto do Patrimônio Histórico e Artístico Nacional (IPHAN) em 1937. Para ele "A educação popular é o meio mais eficaz de assegurar a defesa do patrimônio histórico e artístico nacional"(4).

Uma mudança legal- estabelecida na Portaria № 230, de 2002, emitida pelo IPHAN determinou a necessidade de elaboração e execução de um Programa de Educação Patrimonial junto às pesquisas arqueológicas desenvolvidas. Com isso, os arqueólogos brasileiros passaram a ter responsabilidades que incluem não somente a produção das informações científicas, mas também o envolvimento da comunidade na gestão do patrimônio. $\mathrm{O}$ ponto crítico comum a todos os projetos é a falta de um apoio financeiro sistemático. Grande parte das verbas é oriunda de instituiçôes de fomento à pesquisa, ou verbas cedidas por municípios, que variam de acordo com as prioridades políticas conjunturais (5).

Nem sempre apenas a Arqueologia é suficiente para se ter conclusóes mais efetivas sobre os estudos realizados e também de cuidar de todo o patrimônio encontrado. A Arqueometria é uma área interdisciplinar, a qual integra conceitos de engenharia de materiais, desenho industrial, educação artística, história e arqueologia, que estuda artefatos de origem arqueológica. A importância desse tipo de estudo reside no fato que os artefatos cerâmicos refletem a compreensão da dinâmica social e cultural dos povos, e que a classificação do material arqueológico, por meio de sua composição química, formas, texturas, microestrutura, pode ser um dos meios para encontrar a procedência da matéria-prima utilizada na fabricação das cerâmicas $(6,7)$.

Historicamente, a cultura dos povos indígenas é conhecida principalmente pelos relatos de cronistas da época do descobrimento, dos primeiros tempos da colonização do Brasil e através de vestígios arqueológicos, expressando os valores coletivos desses primeiros habitantes do litoral brasileiro. Tais manifestaçóes foram reunidas sob o nome "Tradição Tupiguarani” e é dividida em dois domínios, prototupi que consta do Sudeste ao Nordeste da América do Sul, e o protoguarani, localizado ao sul (8).

Recentemente, na cidade de Canas/SP, localizada no Norte do Vale Paraíba, foi descoberto um sítio arqueológico denominado Sítio Arqueológico Caninhas, composto por estruturas funerárias, estruturas de combustão e diversos objetos de uso cotidiano de populaçôes indígenas que habitaram o local. Abre um considerável leque de possibilidades no que diz respeito a estudos relacionados à História e conseqüentemente à memória vinculada ao patrimônio da região. 
A Figura 1 mostra uma estrutura funerária e um forno indígena que foram salvo no sítio arqueológico Caninhas.
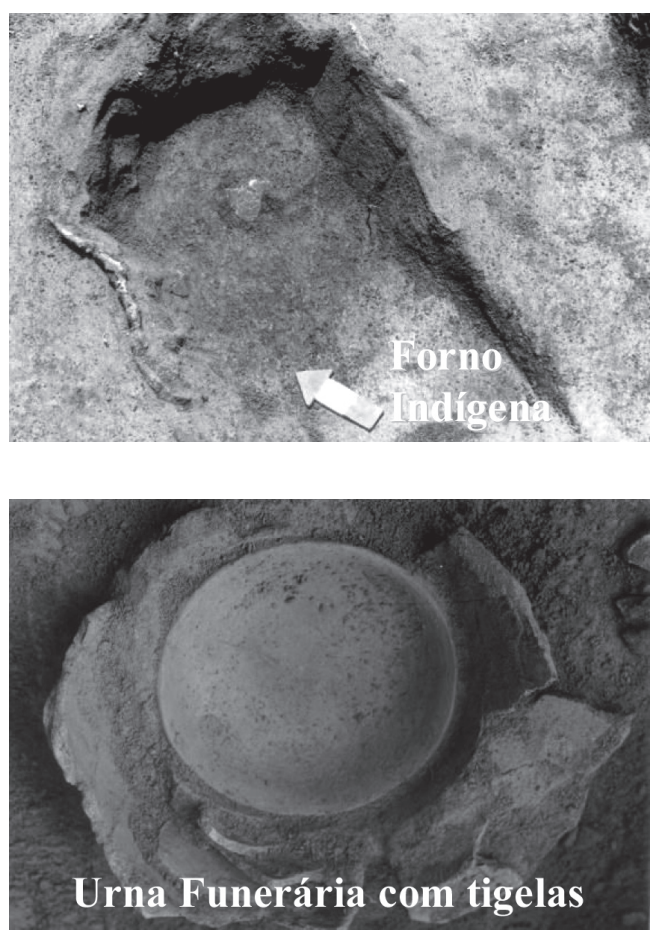

Figura 1

A primeira imagem mostra um forno indígena e a segunda uma urna funerária contendo tigelas, ambos foram salvo no sítio arqueológico Caninhas.

A categoria do sítio arqueológico de Canas é unicomponencial, de natureza pré-colonial, cuja tribo possivelmente é Tupi-guarani, devido características dos utensílios como: conformação das cerâmicas por acordelamento, e pinturas geométricas na cor vermelha, branca e preta. Existiam quatro possíveis unidades habitacionais, com vestígios de material predominantemente cerâmico e lentes de carváo, aparecendo até $40 \mathrm{~cm}$ de profundidade. As estruturas de sepultamento situavam-se fora das ocupações habitacionais indicando padróes culturais de uso do espaço e, em diferentes áreas, sugerindo uma diferenciação e hierarquização do espaço. As urnas continham cerâmicas em vez de corpos, indicando assim, possíveis oferendas, cujo conteúdo ainda náo se encontrava compactado . A pintura presente nos fragmentos encontrados e tigelas recuperadas se encontra em bom estado de conservação, o que indica que a provável ocupação da aldeia tenha acontecido entre os séculos XIV e XVI, mas é necessário maiores investigaçóes para determinar essa gama de possibilidades (9).
A Figura 2 mostra alguns fragmentos de cerâmicas indígenas encontradas no sítio arqueológico Caninhas.
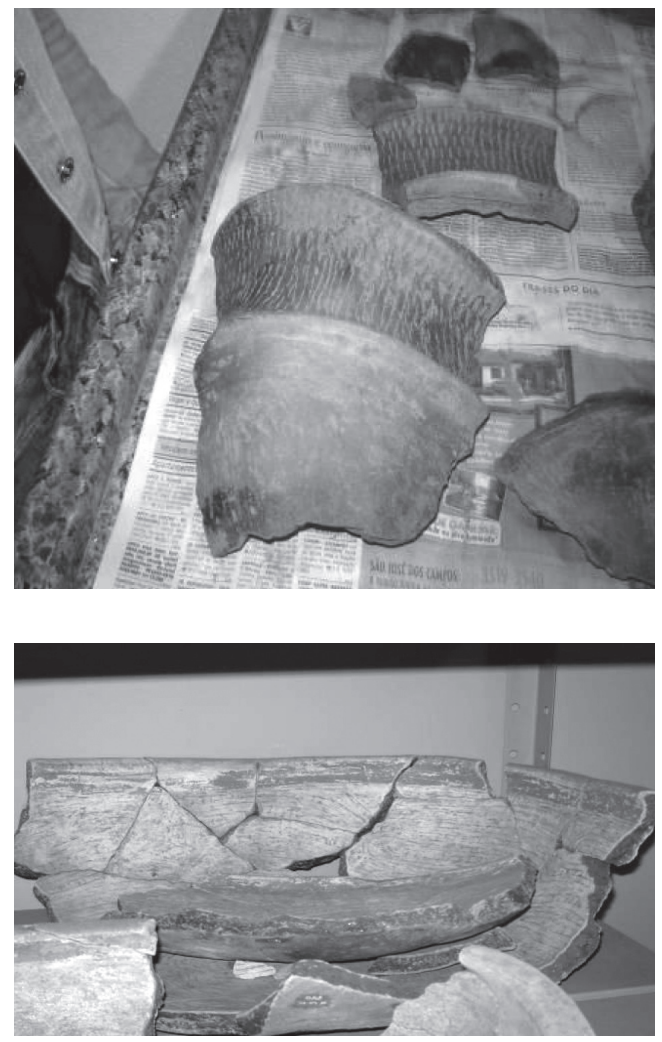

Figura 2 - Fragmentos de cerâmicas indígenas do sítio arqueológico Caninhas - Canas/SP

A experiência brasileira tem demonstrado que a preservação do patrimônio cultural dos sítios arqueológicos depende do envolvimento das comunidades locais, bem como da participação destas nos benefícios decorrentes de atividades econômicas como, por exemplo, o turismo, a criação de museus, comércio de cerâmicas artesanais, etc.

Essa mesma experiência está sendo aplicada na comunidade de Canas, o qual um projeto multidisciplinar tem integrado diversas áreas e níveis de conhecimento, formação de recursos humanos para treinamento e capacitação, integração da comunidade no meio cultural nativo, com objetivo principal a divulgação científica e o fortalecimento dos valores culturais da região. Isso faz com que a comunidade se reconheça enquanto portadora de uma identidade sócio-cultural. O envolvimento da comunidade na pesquisa e o dinamismo do projeto multidisciplinar, além de ser gratificante, elevam o conhecimento a todos os envolvidos e diminui as diferenças sociais por meio da ciência. 


\section{METODOLOGIA}

Os fragmentos e peças provenientes do sítio arqueológico Caninhas foram salvos e inventariados, totalizando 4000 peças. Na etapa de inventário, os jovens de escolas públicas de Canas/SP e alunos de Iniciação Científica, realizaram visitas técnicas ao laboratório de Arqueologia da Fundação Cultural de Jacarehy, para quantificar e montar os utensílios do acervo arqueológico, sendo orientados por arqueólogos. O trabalho de inventário foi uma etapa da Educação Patrimonial, inserindo alunos de diversas áreas ao contexto da arqueologia.

O processo de inventário foi realizado em quatro etapas principais: higienização, numeração, caracterização e montagem. Na higienização dos fragmentos cada fragmento foi lavado com água. Em seguida, o fragmento foi repousado sobre folhas de papel absorvente (ou jornal) para secar até a próxima etapa (numeração).

A numeração consistiu na aplicação de uma fina e pequena camada de esmalte translúcido no canto inferior dos fragmentos. Sobre a camada de esmalte a numeração foi feita com tinta nanquim, indicando o Sítio e sua localização e o número da peça (Exemplo: SP - CA, 01 - 509).

Após numeração, os fragmentos foram separados em grupos que se encaixavam, formando as peças como se fosse um quebra-cabeça. Os fragmentos foram catalogados em fichas, de acordo com sua característica (parte da peça, tipo de antiplástico e queima, local de onde foi retirado, grupo a que pertence, e suas dimensôes). Os pequenos fragmentos foram guardados e a peças agrupadas foram montadas.

Foram realizadas diversas análises químicas, físicas, térmicas, e mecânicas para caracterizar as cerâmicas arqueológicas. Argila atual da região foram sinterizadas em diversas temperaturas e caracterizadas da mesma forma que as cerâmicas arqueológicas para comparação. Em vista aos resultados obtidos, publicou-se em congressos e revistas especializadas $(10,11,12)$. Tão importante quanto às publicaçóes científicas foram os seminários à comunidade, e este é o foco metodológico deste trabalho: incentivar a Educação Informal por métodos de Educação Patrimonial.

Desta forma, cada etapa desenvolvida do projeto foi apresentada seqüencialmente nas escolas da região. Estas palestras eram ministradas por professores coordenadores do projeto, por alunos de iniciação científica, pré-iniciação científica, e também com a colaboração de alguns alunos voluntários do ensino médio da cidade de Canas.

O tema das palestras variou bastante: desde questôes arqueológicas, realizadas no próprio local do sítio arqueológico, modelamento virtual 3D, realizado na Faculdades Integradas Teresa D'Ávila (FATEA), e assuntos referentes a engenharia de materiais, realizadas no Departamento de
Materiais da Escola de Engenharia de Lorena (DEMAR/ EEL/USP), além de diversas palestras abertas a comunidade, realizadas na Casa Cultura de Canas e escolas públicas.

\section{RESULTADOS}

A economia de Canas está voltada a agricultura e à cerâmica artesanal em que, segundo dados do Instituto Nacional de Estudos e Pesquisas Educacionais Anísio Teixeira (INEP), estão entre as piores notas do Exame Nacional do Ensino Médio (ENEM). As cidades vizinhas são maiores (mais de 100 mil habitantes), mas são constituídas por enorme quantidade de jovens sem perspectiva de emprego e fonte de renda. A realizaçáo deste projeto tem aberto a iniciativa por parte da prefeitura e algumas empresas da região, em formar parcerias para desenvolver um produto cerâmico nativo, com características indígenas.

Por falta de conhecimento, a comunidade de Canas tinha medo do acervo arqueológico e as possíveis conseqüências de seu estudo. Hoje existe o envolvimento da comunidade local, para sustentar a exploração arqueológica, sua divulgação, e, principalmente, atuar como guardiã desse patrimônio.

A Figura 3(a) mostra uma apresentação da equipe multidisciplinar no sítio Arqueológico "Caninhas", para nivelamento das informaçóes. Os profissionais de Arqueologia da Fundação Cultural de Jacarehy falaram sobre a descoberta do Sítio arqueológico Caninhas e o trabalho de salvamento realizado no local, esclarecendo dúvidas sobre a tradição Tupiguarani e as possíveis rotas efetuadas pelos índios no Vale do Paraíba.

A Figura 3(b) mostra um seminário apresentado por um aluno de Pré-IC bolsista da Universidade de São Paulo (USP), para alunos de ensino médio de escolas públicas da região.

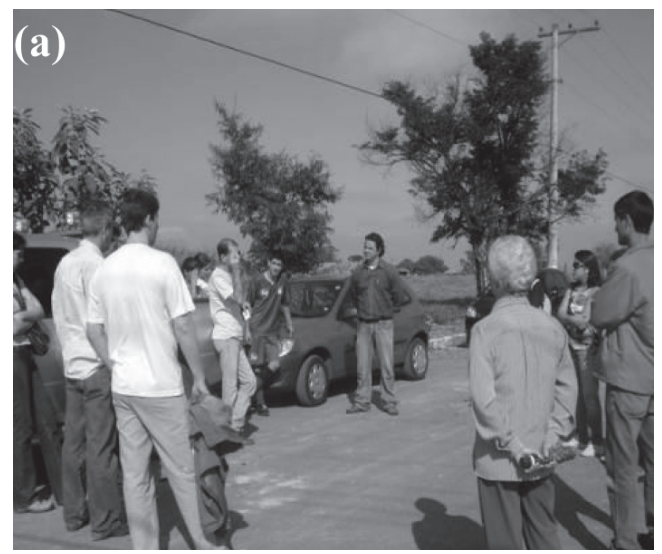




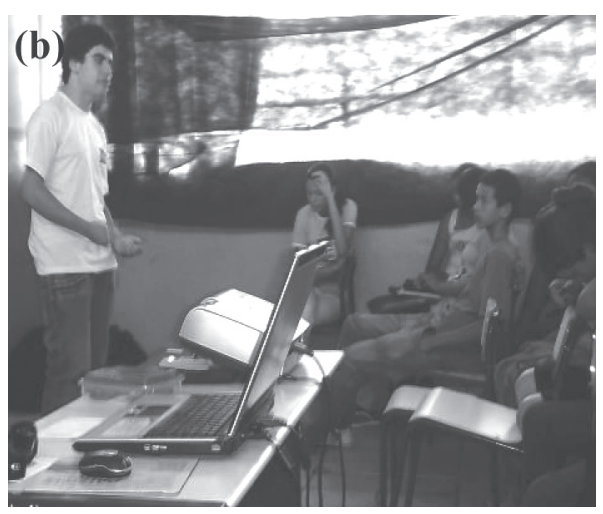

Figura 3 - Apresentação da equipe multidisciplinar em Canas/SP: (a) Visita ao Sítio Arqueológico Caninhas; (b) Seminário em escola pública.

A Figura 4 mostra a visita de alunos da rede pública de Canas, à Fundação Cultural de Jacarehy, onde foi realizado o Inventário das cerâmicas arqueológicas. Em (a) é mostrado o processo de higienização, em (b) a numeraçáo e em (c) a reconstituição das cerâmicas arqueológicas de uma tigela cerimonial de porte pequeno e uma tigela de porte grande. Ambas as peças continham pinturas comum à tradição $\mathrm{Tu}$ piguarani - fundo branco, com faixas vermelhas e grafismos em linhas pretas.
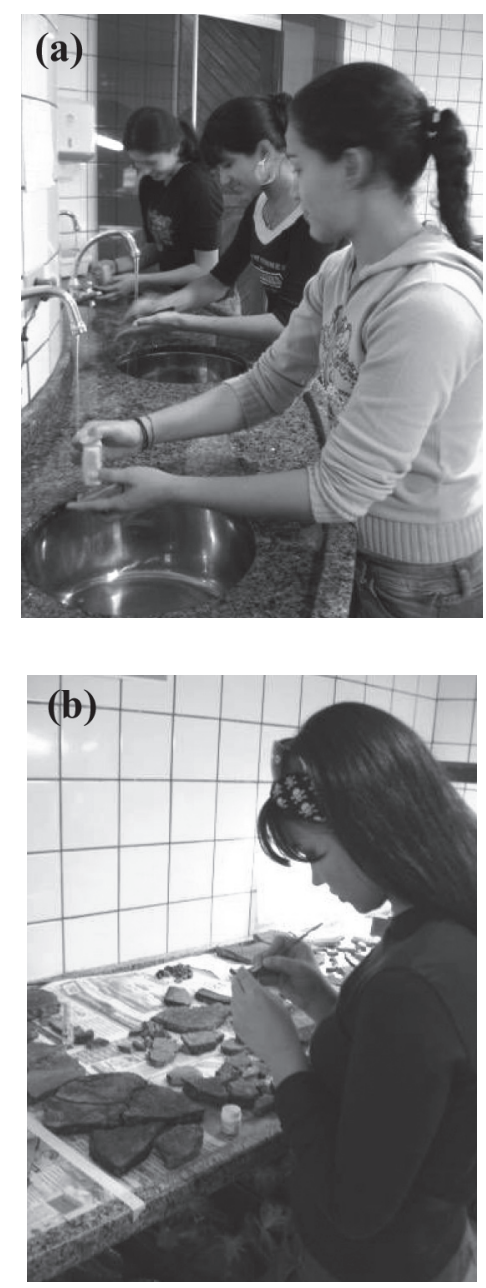

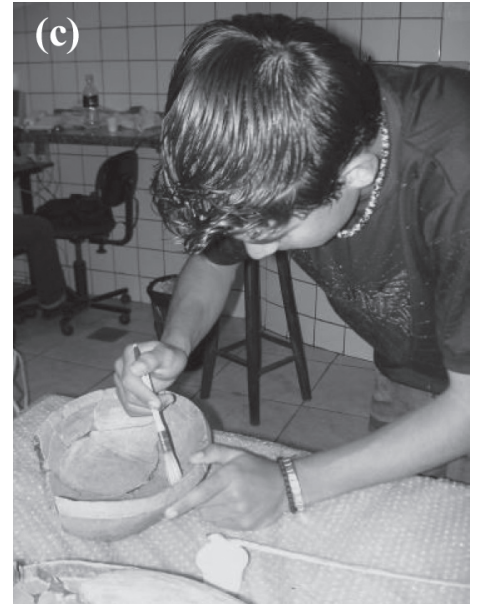

Figura 4 - Visita da equipe à Fundaçáo Cultural de Jacarehy:

(a) Higienização;

(b) Numeração; (c) Reconstituição das cerâmicas arqueológicas.

\section{CONSIDERAÇÓES FINAIS}

O desenvolvimento de projeto multidisciplinar aplicando a Educação Patrimonial é de suma importância para a região do Vale do Parába, pois, além de viabilizar todo o estudo das cerâmicas arqueológicas do acervo de Canas, também auxiliará para o estudo do ciclo indígena (deslocamento) na regiấo. A iniciativa envolve pessoas de diversas áreas e de níveis de conhecimento, interando a comunidade com o intuito desenvolver a educação informal, incluindo as escolas da rede pública e privada da regiáo e outros ambientes de apoio à educaçáo, o resgate cultural e, conseqüentemente, o desenvolvimento sustentável.

\section{AGRADECIMENTOS}

Agradecemos ao CNPq pela bolsa de IC e auxílio pesquisa (processo 121418/2008-1 e processo 481703/2008-0), a bolsa de Pré-IC fornecida pela USP. 


\section{REFERÊNCIA}

(1) ORIÁ, Ricardo. Educação patrimonial: conhecer para preservar. Portal Educacional, (S.l.:entre 1999 e 2009). Disponível em <http://www.educacional.com.br/articulistas/ articulista0003.asp>. Acesso em: 30 agosto 2009.

(2) CRUZ, A. V. Uma análise pluralista do cooperativismo como proposta de proteção aos bens culturais: novas perspectivas para os acervos arqueológicos com identidade indígena. Dissertação de Mestrado, Universidade Federal do Paraná, Paraná, 2006.

(3) HARTOG, F., Tempo e patrimônio. In: . Varia historia, Belo Horizonte, 2006, v. 22, n. 36, p.261-273.

(4) Força Aérea Brasileira. Em Dia Com O Que Acontece Na Fab. Disponível em: <http://

www.fab.mil.br/portal/acontecefab/mostra_conversapol. php?id=92>. Acesso em: 30 agosto 2009.

(5) BELISÁRIO, Roberto. Carbono-14 não é único método de datação. Arqueologia. Com Ciência, Campinas, UNICAMP, n. 47, setembro de 2007, Disponível em: <http://www.

comciencia.br/reportagens/arqueologia/arq06.shtml>. Acesso em: 30 agosto 2009

(6) NUNES K. P.; TOYOTA. R. G.; OLIVEIRA P. M. S.; NEVES E. G.; MUNITA C. S. Estudo dos elementos traço nas cerâmicas do sítio arqueológico Hatahara. In: ENCONTRO LATINO AMERICANO DE INICIAÇÃO CIENTÍFICA, 12, e ENCONTRO LATINO AMERICANO DE PÓS-GRADUAÇÃO, 8. São José dos Campos: Universidade do Vale do Paraíba, 2008.

(7) MACHADO, N. T. G.; SCHNEIDER, P.; SCHNEIDER, F. Análise parcial sobre a arqueológica do Vale do Taquari-RS. Revista Cerâmica, n. 54, p. 103-109, 2008.

(8) PROUS. A. Arqueologia. Revista Ciência Hoje, Rio de Janeiro, v. 36, n. 213, p. 22-28, 2005. Disponível em: http://cienciahoje.uol.com.br/controlPanel/materia/resourcel download/41398. Acesso em: 30 agosto 2009.

(9) BORNAL, W. G., QUEIROZ, C. M. Relatório das escavaçóes do sítio Caninhas. Jacarei: Fundação Cultural de Jacarehy. 2005. 36. p.
(10) MATOS, C.C.; NAKANO, F. P.; TAGUCHI, S. P., RIBEIRO, R. B.; ROSA, S. J. L., CAMARGO-VERNILLI, D., Comparação da microestrutura e da composição de cerâmicas indígenas provenientes do sítio arqueológico caninhas, com as obtidas atualmente na região. In: CONGRESSO BRASILEIRO DE CERÂMICA,53, 2009, Guarujá. Anais... Guarujá, 2009.

(11) NAKANO, F. P.; RIBEIRO, R. B.; ROSA, S. J. L.; BORNAL, W. G.; QUEIROZ, C. M.; TAGUCHI, S. P. Análise microestrutural, composicional e propriedades mecânicas das ceramicas indígenas do sítio arqueológico Caninhas/SP. In: CONGRESSO BRASILEIRO DE CERÂMICA,53, 2009, Guarujá. Anais... Guarujá, 2009.

(12) SARA, J. L.; NAKANO, F. P.; MATOS, C. C.; QUEIROZ, C. M.; TAGUCHI, S. P.; RIBEIRO, R. B. Linguagem multidisciplinar: da Ciência à comunidade. In: OLIVEIRA, N. A. A. de. Comunicação sob múltiplos olhares. Lorena: Grafist, 2009. p. 232-241.

Endereço para Correspondência:

Rosinei Ribeiro Batista rosinei.ribeiro@foa.org.br Mestrado Profissional em Ensino em Ciências da Saúde e do Meio Ambiente

Centro Universitário de Volta Redonda Campus Três Poços Av. Paulo Erlei Alves Abrantes, no 1325 , Três Poços - Volta Redonda / RJ CEP: 27240-560 